\title{
Programming as an Option for Females in Undergraduate Studies
}

\author{
Diana M. López Robledo a,* \\ ${ }^{a}$ University of Puerto Rico in Ponce - Business Administration and Computer Science Department, Ponce, \\ Puerto Rico, USA
}

Received: 18 June 2018; Accepted: 16 October 2018; Published: 08 January 2019

\begin{abstract}
A gender gap exists in undergraduate studies of different careers related to technology. Previous research investigated differences among gender in Science, Technology, Engineering, and Mathematics (STEM) careers and other investigated what influences females to choose a career in computer science. Therefore, an exploratory study was conducted to examine high school student's perceptions about a technology career in Puerto Rico. The participants on this study were students in different private and public high schools in Puerto Rico, specifically sophomores, juniors and seniors' females. A sample (n) of 26 female students answered a questionnaire after attending an introductory programming workshop. All of the participants considered the programming workshop as a good experience and they would be interested in attending, and also recommend other girls to attend, future programming events. Results suggest that the highest influence for them to pursue undergraduate studies on a technology program comes from female teachers, mother, and male teachers.
\end{abstract}

Index Terms: Programming, females, STEM, high school, Puerto Rico, gender gap, role model.

(C) 2019 Published by MECS Publisher. Selection and/or peer review under responsibility of the Research Association of Modern Education and Computer Science.

\section{Introduction}

Research in different countries has focused on the participation of women in computer science and other technology related fields, making emphasis that there is a gender gap. Lynn [6] published an article in PC Magazine, in which the author recognizes the presence of women with technical skills, emphasizing that there are many women but they aren't acknowledged. The article critiques the newspaper's need to attract followers on social media, although there are few articles about female programmers, system administrators, storage or networking engineers, there are many females in these positions. There is also a gender gap in undergraduate students of different technology careers, in different countries including Puerto Rico [2, 5, 7, 10, 11]. Several

* Corresponding author.

E-mail address: diana.lopez2@upr.edu 
authors have investigated what influences females to choose a career, what serves as barriers and facilitators to choose one related to technology and what motivates females to complete it and enter the workforce.

A study was conducted to examine high school students' perceptions about a technology career as an option for females in Puerto Rico. The paper is organized as follows. The introductory section is followed by a literature review section. Methodology of the study and description of the sample are then presented, followed by the results, discussion of findings, and conclusions.

\section{Related Work}

Varma \& Kapur [12] found that in India, women constituted $42 \%$ of students in computer engineering programs in 2011. They conducted an investigation to identify why women in India were attracted to computer science through a qualitative study with 60 undergraduate females. On their study, the researchers found that, although participants do not have a computer at home when growing up, they had access to a computer. Some of them were exposed to computers at home, others at cyber cafes or at school. When asked about how they became interested in the technology field, 53\% identified their family as major motivation, $27 \%$ identified promising career prospects, and $15 \%$ of them developed interest in the field with no specific reason. Varma \& Kapur [12] mentioned that only $10 \%$ of the participants were taught basic programming skills while in high school and $77 \%$ of the participants considered mathematics as their best subject in school. Also, participants embraced challenges and identified teachers as knowledgeable, supportive, interactive, and motivators to work hard outside of class. Female gave positive comments about their male peers.

Powel, Dainty, \& Bagilhole [8] suggested that students were influenced by their childhood experiences with some differences among gender (38\% of women and $62 \%$ of men) and they were also encouraged by family members. In this regard, women require more active encouragement to study technology-related fields. Women also perceived technology as a long-term career with employability. In their research, women had a desire to be different and take the challenge of working in a male-dominated industry [8]. They also discussed the finding that participants had gender stereotypes, "the women appear to be distancing themselves from other women, by becoming an exception to the rule". Researchers found that women tend to associate engineering and technology best suited to how the male brain works. Also, the authors suggested implicit in their responses was the idea that technology careers were chosen only by certain types of women. Power et al. [8] furthermore suggested that, although equality seems to have been achieved, entrenched stereotypes continue to persist. In relation to this, information technology (IT) careers have an image problem and perceptions of technology workers need to be changed before high school [3].

Quesenberry \& Trauth [9] conducted a study to explore personal characteristics, individual influences, and societal influences that serve as barriers and facilitators of women's careers in IT. They used qualitative and quantitative inquiries. They used 92 qualitative interviews from women in the IT workforce in the United States and an online questionnaire to 210 women in the IT workforce from different ethnical backgrounds (white, Asian, Hispanic, and African, among others). Results of this study suggest that equality in the organization is important to address gender gap in IT, for example equal pay for equal work and equal treatment to pursue management careers. Likewise, the authors stated that reasons influencing careers chosen by women are based on several constructs, including: life experiences, talents, preferences, and also is affected by the context in which they appear (culture).

Autio [1] identified three women with highest technological competence (within the girls group) in a test performed more than 10 years ago. Technological competence was an aggregate of technological will, technological skill, and technological knowledge. The author tried to identify if the technologically talented females choose technological careers. They found that 2 out of 3 were enrolled in a technological university. However, the study suggests that the process of making choices in the area of technology is more complicated to technologically talented females than for males. The study suggests that as more males are engaged in the technology field, in the long term it may have a strong impact on female's self-confident.

Similarly, Verges [13] conducted a study of 28 women in the IT field through analysis of interviews and 
focus groups. In her study, she analyzed motivation for females to self-include in the technology field, enablers that they encounter, and mechanisms they follow and activate to self-include. Findings suggest that females shared curiosity, passion, and interest for technology as their main motivations for self-inclusion. They also mentioned challenges in the field, creativity, and innovation. Verges [13] states that females had some facilitators in their context, which makes it more feasible to self-include in the technology field. Some of the facilitators are: motivation from relatives, participation in associations and events related to IT, and role models.

In a study conducted with more than 500 students of bachelor degrees from different public and private universities in Puerto Rico, López [5] found that family and parents' support is significant for females who choose a career in a technology-related field, even when they may not be aware of the existing gender gap. The study also concluded that academic institutions need to provide role models in the technology field so they can engage in providing guidance to young females, develop different opportunities for females and involve them in Science, Technology, Engineering, and Math (STEM) workshops. In the same way, the study recommended to prepare workshops directed to females in high school, so they can expose themselves to the IT field, get involved with role models, and consider pursuing an IT related career.

\section{Methodology}

The participants on this study were females who demonstrated interested in technology and computer science that attended the workshop for seven hours on Saturday, April 2, 2016. Most of them were taken by their parents, while others attended the workshop with their teachers or friends. The workshops were given by undergraduate students enrolled in the Computer Information Systems Program at the University of Puerto Rico in Ponce (UPRP) in their third or fourth year of study. At the end of the workshops, the objectives of the study were explained to the parents and consent was requested before answering the questionnaire. Furthermore, the objectives of the investigation were explained to students and they were asked to answer the questionnaire if they wanted to participate in the study, as their participation was voluntary.

The survey was anonymous, but included questions about age and high school grade they were currently enrolled. It also asked about their intentions to pursue undergraduate studies, either in a computer-related field or not. They were also asked to identify people who motivated them or influenced them on pursuing a career related to technology. Data was analyzed using IBM Statistics Software version 21. A reliability statistics analysis was made on 33 items of the questionnaire with the complete sample. Cronbach's Alpha coefficient obtained in the analysis was 0.898 . Therefore, the instrument meets the requirements of internal reliability as it is above 0.75, as suggested by Hernández, Fernández, and Baptista [4].

\section{Results and Discussion}

The sample of the study is composed of 26 females, range from 14 to 17 years old $(\mu=15.65 ; \sigma=0.797)$. With regard to age, $42 \%$ of the sample was 15 years old, $39 \%$ was 16 years old, $15.4 \%$ was 17 years old and $4 \%$ was 14 years old. One (1) participant was from ninth grade (4\%), fifteen (15) participants were from tenth grade (58\%), eight (8) participants were from eleventh grade (31\%), and two (2) participants were from twelfth grade $(8 \%)$. The participants represented five different schools in Puerto Rico, mainly from public schools $(81 \%)$.

The results indicated that $62 \%$ of the participants have good skills with technology, $54 \%$ have good skills with computers, $73 \%$ are interested in learning new topics related to technology, and $81 \%$ are curious about how computers, programs and/or applications works. The participants were asked if they had participated in previous workshops at the University of Puerto Rico in Ponce. The results show that $19 \%$ of them had attended previous workshops at the Institution. However, 96\% said that they had never participated in previous programming workshops at the Institution. On the other hand, $15 \%$ of the females responded that they had participated in programming workshops at other institutions.

The participants were asked if they had previous experience or knowledge about computer programming and 
if they had access to a computer. Table 1 shows that most of them had access to a computer at school and also at home. Some of the participants $(35 \%)$ had previous knowledge about computer programming before attending the workshop at University of Puerto Rico in Ponce. Twenty-three percent (23\%) said that their school offers basic programming courses. However, most of them do not take programming courses at school $(92 \%)$.

Table 1. Previous Experience and Access to Computer

\begin{tabular}{lccc}
\hline Item & Yes & No & Don't Know \\
\hline Previous programming knowledge & $34.6 \%$ & $57.7 \%$ & $7.7 \%$ \\
Access to computer at home & $96.2 \%$ & $3.8 \%$ & - \\
Access to computer at school & $92.0 \%$ & $8.0 \%$ & - \\
Programming courses at school & $23.1 \%$ & $69.2 \%$ & $7.7 \%$ \\
Enrolled in programming courses & $8.0 \%$ & $92.0 \%$ & - \\
\hline
\end{tabular}

The instrument included few questions related to the participant's opinion about the computer programming workshop offered. A five point Likert scale was used: $1=$ Totally Disagreed, $2=$ Disagreed, $3=$ Neutral, $4=$ Agreed, 4 = Totally Agreed. Table 2 presents responses in three columns, where option 1 and 2 were joined as one column (Disagreed), the second columns represents option 3 (Neutral), and option 4 and 5 were considered as one column (Agreed). All of the participants (100\%) considered the workshop as a good experience (15\% agreed, $85 \%$ totally agreed). Participants also responded that they would be interested in attending a future programming event at the Institution (19\% agreed, $81 \%$ totally agreed). They considered that the information provided was relevant to the topic. They also considered that the workshop helped them understand better what computer programming is.

Table 2. Perception of the Programming Workshop Experience

\begin{tabular}{|c|c|c|c|}
\hline Opinion & Disagreed & Neutral & Agreed \\
\hline The workshop helped me understand better what computer programming is. & 3.8 & 3.8 & 92.4 \\
\hline $\begin{array}{l}\text { I think that basic programming workshops are a good opportunity for high } \\
\text { school students. }\end{array}$ & - & 3.8 & 96.2 \\
\hline The information provided at the workshops was relevant. & - & 8.0 & 92.0 \\
\hline The time used for the activity was appropriate. & - & 11.5 & 88.5 \\
\hline In general, attending the workshop was a good experience. & - & - & 100.0 \\
\hline $\begin{array}{l}\text { I would be interested in attending a future programming event at the } \\
\text { Institution. }\end{array}$ & - & - & 100.0 \\
\hline $\begin{array}{l}\text { I would recommend other girls to attend future programming events at the } \\
\text { Institution. }\end{array}$ & - & - & 100.0 \\
\hline
\end{tabular}

The participants considered programming workshops as good opportunities for high school students. All of the participants $(100 \%)$ are willing to recommend other girls to attend future programming events at the Institution (20\% agreed, $80 \%$ totally agreed). Results suggest that the workshops met the expectations to present an idea about the computer science field and a basic programming experience to young females interested in technology. This is demonstrated as it was the first experience for most of the participants and they would be willing to attend to a future programming event.

The participants were asked about motivation from different people to attend the workshop, including parents, friends, counselors, and teachers. Results are shown on Table 3. They reveal that female friends had the greatest influence on their decision to attend the workshop, followed by female school counselors. 
Table 3. Motivation to Attend the Programming Workshop

\begin{tabular}{lccc}
\hline Motivation & Disagreed & Neutral & Agreed \\
\hline Mom & 3.8 & 30.8 & 65.4 \\
Dad & 26.9 & 11.5 & 61.5 \\
Family Members & 24.0 & 28.0 & 48.0 \\
Female Teachers & 12.0 & 20.0 & 68.0 \\
Male Teachers & 24.0 & 8.0 & 68.0 \\
Female School Advisor & 19.2 & 7.7 & 73.1 \\
Male School Advisor & 27.2 & 13.6 & 59.1 \\
Female Friends & 12.5 & 12.5 & 75.0 \\
Male Friends & 19.2 & 19.2 & 61.5 \\
\hline
\end{tabular}

All of the participants stated that they have the intention to enroll on an undergraduate program after high school (12\% agreed, $88 \%$ totally agreed). However, $35 \%$ are considering to pursue a computer-related career for their undergraduate studies (15\% agreed, 19\% totally agreed). There is a slightly higher percent (39\%) that remained "neutral" on this assumption, which can be because they have not yet decided what to study. They are not decided, either to study a computer oriented career or not. Some of the participants (23\%) are not considering computer field as a choice for undergraduate studies (12\% disagreed, $12 \%$ totally disagreed).

Table 4 shows what participants responded about who motivate them to purse a computer-related career after graduating from high school. The highest influences reported by the participants are female teachers, mother, and male teachers.

Table 4. Motivation for Undergraduate Studies in Computer Science

\begin{tabular}{llll}
\hline Motivation & Disagreed & Neutral & Agreed \\
\hline Mom & 30.7 & 23.1 & 46.1 \\
Dad & 41.6 & 20.8 & 37.5 \\
Family members & 42.3 & 23.1 & 34.6 \\
Female teachers & 25.0 & 16.7 & 58.4 \\
Male teachers & 26.9 & 26.9 & 46.1 \\
Female friends & 34.6 & 23.1 & 42.3 \\
Male friends & 34.6 & 23.1 & 42.3 \\
\hline
\end{tabular}

Students were asked to mention (in an open ended question) what was the best part about the workshop. The participants provided different answers, which were analyzed based on the content. Responses are shown on Table 5, including coding, dynamics, strategies, and help provided to them by speakers, and others (friendliness, food). Also, $38.5 \%$ of the participants mentioned "all".

Table 5. Best Part About the Workshop

\begin{tabular}{lcc}
\hline \multicolumn{1}{c}{ Comment } & Frequency & Percent \\
\hline Coding & 7 & $26.9 \%$ \\
Dynamics, Strategies and Help & 4 & $15.4 \%$ \\
Others & 5 & $19.2 \%$ \\
Everything & 10 & $38.5 \%$ \\
\hline
\end{tabular}


On the other side, students were asked to mention (in an open ended question) what they didn't like about the workshop. Among the 26 responses, most of them stated that they like everything about it. However, one participant mentioned that it was necessary to include more female teachers, which refers to ushers who help in the individual explanation. Two participants mentioned speed of presentation and one participant mentioned complexity of the exercises. These comments would be taken into consideration for future workshops as it is of high importance to improve future student's experiences.

After analyzing responses on descriptive statistics and frequency, additional correlation analysis was performed. Correlation analysis was made between eight items included in the instrument with statements evaluated on a 5-point Likert Scale. The variables are: (1) job opportunities if they study a career related to computers, (2) computer science as a good option to enroll for undergraduate studies, (3) intention to pursue undergraduate studies related to computers, (4) interest to learn about technology, (5) curiosity about how computer, programs, and applications works, (6) good skills with technology, (7) good skills with the computer, and (8) importance to learn about use of technology.

A Pearson's correlation was run to determine the relationship between different variables. Table 6 shows results of the correlation analysis. There was a very strong positive correlation $(r=0.904 ; n=26 ; p<.001)$ among the interest in learning about technology and the curiosity about how computer, programs, and applications works. There was a very strong positive correlation $(r=0.808 ; n=26 ; p<.001)$ among considering computer science as a good option for undergraduate studies with having curiosity about how computer works and also with the interest to learn about technology $(r=0.847 ; n=26 ; p<.001)$.

Table 6. Correlation among Different Variables

\begin{tabular}{|c|c|c|c|c|c|c|c|c|}
\hline ID & (1) & (2) & (3) & (4) & (5) & (6) & (7) & $(8)$ \\
\hline (1) & 1 & $.808^{* * * *}$ & $.688^{* * * *}$ & $.647 * * *$ & $.610^{* * * *}$ & $.525 * * *$ & $.524 * * *$ & $.550 * * *$ \\
\hline (2) & & 1 & $.688 * * *$ & $.847 * * *$ & $.808 * * *$ & $.543 * * *$ & $.414 * *$ & $.613 * * *$ \\
\hline (3) & & & 1 & $.536^{* * *}$ & $.493 * *$ & .228 & .220 & $.359 *$ \\
\hline (4) & & & & 1 & $.904 * * *$ & $.484 * *$ & $.342 *$ & $.670 * * *$ \\
\hline (5) & & & & & 1 & $.550 * * *$ & .288 & $.756^{* * *}$ \\
\hline (6) & & & & & & 1 & $.846^{* * *}$ & $.442 * *$ \\
\hline (7) & & & & & & & 1 & $.374 *$ \\
\hline (8) & & & & & & & & 1 \\
\hline
\end{tabular}

*Significant at $0.10 ; * *$ Significant at $0.05 ; * * *$ Significant at 0.01

A very strong correlation $(r=0.846 ; n=26 ; p<.001)$ was found among having good skills with the computer and good skills with technology. A very strong significant correlation $(r=0.808 ; n=26 ; p<.001)$ was also found between considering computer science as a good option for undergraduate studies and considering that there would have job opportunities if they study a career related to computers. A strong correlation $(\mathrm{r}=0.756$; $\mathrm{n}=26 ; \mathrm{p}<.001$ ) was found among curiosity about how computer works and importance to learn about use of technology. Additional strong and moderate correlations were found among variables, as shown in Table 6.

\section{Conclusions}

Gender gap in the technology field has been the focus of several investigations around the world. It is included in (Science, Technology, Engineer, and Mathematics) STEM projects, which aims to include more students interested in those fields. In Puerto Rico, it is a current topic of interest among different public and private schools, including universities. Most of the sample in the study has access to a computer at their school 
and at home, but they have no programming experience. However, high schools are not providing programming courses for their students in their curriculum as they include science or mathematics.

The workshop provided was a good experience for the female students who were interested in the computer science field. Participants are willing to take part in future programming events at the Institution. Some of the participants are considering computer science as an option for undergraduate studies while others have not decided yet. The study identified that those who consider computer science as a good option for undergraduate studies also had interest to learn about technology.

It is suggested that institutions provide additional opportunities for them to engage in the field to provide guidance, and also to serve as role models. Suggested activities may include programming workshops, including basic programming skills and intermediate programming skills. This way, females may interact with technology, be involve in networking with current female undergraduate studies, and also engage in technology as an option for their career path.

\section{References}

[1] Autio, O. (2013). When Talent Is Not Enough: Why technologically talented women are not studying technology. Journal of Technology Education, 24(2), 14-30.

[2] Etzkowitz, H. \& Ranga, M. (2011). Gender Dynamics in Science and Technology: From the "Leaky Pipeline" to the "Vanish Box". Brussels Economic Review, 54(2/3), 131-147.

[3] Harris, N., Cushman, P., Kruck, S., \& Anderson, R. (2009). Technology Majors: Why are women absent?. Journal of Computer Information Systems, 50(2), 23-30.

[4] Hernandez, Fernández and Baptista. (2010). Metodología de Investigación, $5^{\text {th }}$ Edition. McGraw Hill.

[5] López, D. (2015). Perceptions from Students in Puerto Rico about Information Technology Professionals. Journal of Computer Science and Information Technology. Vol. 3, No. 2; December 2015, pp 39-56. ISSN 2334-2366 Print, 2334-2374 Online.

[6] Lynn, S. (2013). There Are Plenty of Women in Tech. PC Magazine, 43-45.

[7] Martínez, L.; Lugo, I.; Rivera, M. (2007). Participación y Representación por Género en Educación Superior. Consejo de Educación Superior de Puerto Rico.

[8] Powell, A., Dainty, A. \& Bagilhole, B. (2012). Gender Stereotypes Among Women Engineering and Technology Students in the UK: Lessons from career choice narratives. European Journal of Engineering Education, 37(6), 541-556.

[9] Quesenberry, J. \& Trauth, E. (2012). The (Dis)placement of Women in the IT Workforce: An investigation of individual career values and organizational interventions. Information Systems Journal, 22(6), 457-473. doi:10.1111/j.1365-2575.2012.00416.x

[10] Soe, L. \& Yakura, E. (2008). What's Wrong with the Pipeline? Assumptions about gender and culture in IT work. Women's Studies, 37(3), 176-201. Doi:10.1080/00497870801917028.

[11] Varma, R. \& Hahn, H. (2008). Gender and the Pipeline Metaphor in Computing. European Journal of Engineering Education, 33(1), 3-11.

[12] Varma, R. \& Kapur, D. (2015). Decoding Femininity in Computer Science in India. Communications of the ACM, 58(5), 56-62. Doi:10.1145/2663339.

[13] Verges, N. (2012). De la exclusión a la autoinclusión de las mujeres en las TIC. Motivaciones, posibilitadores y mecanismos de autoinclusión. Athenea Digital (Revista de Pensamiento e Investigación Social), 12(3), 129-150. 


\section{Authors' Profile}

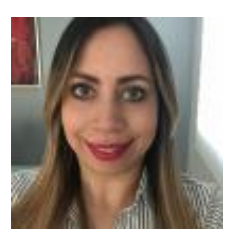

Diana M. López Robledo is an Assistant Professor in Business Administration and Computer Science Department at University of Puerto Rico in Ponce. She has received a DBA from University of Turabo and a Master of Science in Management Information Systems from Florida International University.

How to cite this paper: Diana M. López Robledo,"Programming as an Option for Females in Undergraduate Studies", International Journal of Education and Management Engineering(IJEME), Vol.9, No.1, pp.1-8, 2019.DOI: $10.5815 / \mathrm{ijeme} .2019 .01 .01$ 